\title{
High Genetic Diversity, Phenotypic Uniformity, and Evidence of Outcrossing in Sclerotinia Sclerotiorum in the Columbia Basin of Washington State
}

\author{
Z. K. Atallah, B. Larget, X. Chen, and D. A. Johnson
}

First author: Department of Plant Pathology, University of Wisconsin, Madison 53706; second author: Departments of Botany and Statistics, University of Wisconsin, Madison 53706; and third and fourth authors: Department of Plant Pathology, Washington State University, Pullman 99164.

Accepted for publication 19 February 2004.

\begin{abstract}
Atallah, Z. K., Larget, B., Chen, X., and Johnson, D. A. 2004. High genetic diversity, phenotypic uniformity, and evidence of outcrossing in Sclerotinia sclerotiorum in the Columbia Basin of Washington State. Phytopathology 94:737-742.

Sclerotinia sclerotiorum, the causal agent of potato stem rot, is prevalent and poorly managed on potatoes in the Columbia Basin of Washington. Because of the ubiquitous nature of the fungus and high crop diversity within the Columbia Basin, understanding the population structure and the potential for outcrossing of the pathogen would be helpful in developing disease management strategies. The population structure of S. sclerotiorum in the Columbia Basin from potato was examined using microsatellite markers and mycelial compatibility. Analysis of molecular variance revealed that $92 \%$ of the variability among 167 isolates was found within subpopulations, with limited, yet statistically significant

impact of the collection date, but not the year or location of collection. Linkage disequilibrium and index of association analyses noted a potential for outcrossing in two locations, which was substantiated by the discovery of recombinant ascospores in three field-generated apothecia from the 12 apothecia examined. Microsatellite haplotypes were not correlated with mycelial compatibility groups. This high haplotypic diversity did not seem to impact pathologically important phenotypes. Greenhouse inoculations of potato plants exhibited no significant differences in aggressiveness on potato stems. Moreover, in vitro studies of response to fungicides and temperature stimuli yielded no significant differences among studied isolates. These findings illustrate the potential for outcrossing in warm temperate regions of North America, where a diversity of crops are planted simultaneously and in neighboring fields. This study also indicates that the unsatisfactory management of potato stem rot is likely not directly attributable to genetic factors, but to gaps in agricultural practices.
\end{abstract}

Sclerotinia sclerotiorum (Lib.) de Bary, an ascomycetous fungus, causes disease on more than 400 host species $(6,24)$. $S$. sclerotiorum is described as a homothallic fungus dispersed by airborne ascospores and soilborne sclerotia. Epidemics of potato stem rot are initiated when airborne ascospores land on open potato blossoms attached to the canopy (3). Infested flowers fall on stems and on the ground and fungal mycelia rapidly colonize the blossoms. Stems or leaves contacting colonized blossoms acquire the disease. Ascospores were found to cause the vast majority of observed lesions in the Columbia Basin, and flower removal or fungicide applications at initial full bloom (full bloom of primary flower clusters) drastically reduced disease incidence (3). Also, evidence of myceliogenic germination was observed in 1 of 10 fields during one of two growing seasons, and affected less than $5 \%$ of observed plants.

The population of $S$. sclerotiorum on canola, in Canada, was clonal $(8,15,17)$, with a single clone repeatedly isolated over 4 years across 2,000 km (2). While limited outcrossing was observed in North Carolina and California $(8,16)$, studies conducted in Canada produced no indication of sexual recombination, but could not overrule its occurrence $(15,17)$. Comparisons between wild and agricultural populations of $S$. sclerotiorum in Norway exhibited tendencies for genotypic uniformity of isolates from potato and canola, with greater genetic diversity found among isolates from wild Ranunculus ficaria (buttercup, lesser celan-

Corresponding author: Z. K. Atallah; E-mail address: atila@plantpath.wisc.edu

Publication no. P-2004-0429-01R

(C) 2004 The American Phytopathological Society dine) (19). The latter populations of $S$. sclerotiorum were characterized by spatial structuring, whereas agricultural populations showed a random distribution of genotypes.

Mycelial compatibility groupings (MCGs) and DNA fingerprinting have been used to assess populations of S. sclerotiorum. Mycelial incompatibility is described as a failure of different strains to fuse and form one colony and is characterized by the formation of a barrage of dead cells between two incompatible colonies (20). However, this technique does not allow the identification of heterokaryons (21).

Simple sequence repeats (SSR) or microsatellite loci have been successfully used for intraspecific population studies to investigate genetic structuring of populations $(5,14,31)$, because they are widely dispersed and evenly distributed in the genome of eukaryotes $(11,30)$. The advantages of microsatellites over other markers, such as random amplified polymorphic DNAs, are their high specificity, reproducibility, polymorphism, and codominance. The high variability of microsatellite markers is thought to improve the ability to differentiate among individuals of a clonal organism such as S. sclerotiorum. Microsatellite markers have also been used to detect potential outcrossing in fungi previously thought to perpetuate asexually exclusively (31).

There is no published information on the population structure and the potential for sexual recombination of S. sclerotiorum in the U.S. Pacific Northwest. Also, studies have not been completed on phenotypic characteristics of the population, including aggressiveness on potato (the quantity of disease induced by a pathogenic strain on a susceptible host) and response to fungicides. Such information is critical to improve the management of Sclerotinia stem rot on potato in the Columbia Basin. 
The objectives of this study were to (i) elucidate the population structure of $S$. sclerotiorum on potato in the Columbia Basin of Washington; (ii) examine the potential for outcrossing in the Columbia Basin; and (iii) quantify the aggressiveness to potato, response to fungicides, and growth at various temperatures of S. sclerotiorum haplotypes.

\section{MATERIALS AND METHODS}

Isolates. Isolates of $S$. sclerotiorum were collected in four potato fields in the Columbia Basin of Washington (Table 1). In 2000 , isolates were obtained from potato stem lesions at four different dates in one field in Othello, WA (field OT); samples were obtained from a randomly selected plot $(10$ by $10 \mathrm{~m})$ (Table 1). In 2001, potato isolates were collected from two fields located southwest and north of Pasco, WA (fields SP and NP, respectively) and one field near Warden, WA (field WD). Fields were separated by more than $50 \mathrm{~km}$ and were chosen not to fall in the direction of predominant winds from each other. Isolates were collected in a three-row by 5-m plot using three methods. (i) Prior to initial full bloom, plates of a semiselective medium (29) were exposed on top of plant canopies for 30 min between 9:00 a.m. and 2:00 p.m. to capture ascospores (13). All viable ascospores growing on the petri dish were included in this study. (ii) At initial full bloom, five flowers were collected from the canopy of the same plant on which petri dishes were exposed, and plated on the same semiselective medium. All colonies of $S$. sclerotiorum growing from the latter flowers were included in this study. (iii) At first disease appearance, about 14 to 20 days following row closure, potato stems with lesions were collected and S. sclerotiorum was recovered on potato dextrose agar (PDA).

A total of 167 isolates were included in this study (Table 1). All isolates were purified by transferring single hyphal tips to petri dishes containing PDA, and generated sclerotia were stored at $-20^{\circ} \mathrm{C}$ until used.

Genetic diversity: MCG. MCG tests were conducted on all 167 isolates (Table 1). Two-millimeter-diameter mycelial plugs were obtained from the edge of colonies growing on PDA. Three mycelial plugs were paired in 6.5-cm-diameter petri dishes containing PDA amended with $175 \mu \mathrm{l}$ of McCormack's red food coloring per liter of culture mecium $(20,23)$. Petri dishes were incubated in the dark at $26^{\circ} \mathrm{C}$ for 7 days. Pairings of the 167 were

TABLE 1. List of potato isolates of Sclerotinia sclerotiorum collected from the Columbia Basin of Washington

\begin{tabular}{|c|c|c|c|c|}
\hline Location & $\begin{array}{l}\text { Field } \\
\text { code }\end{array}$ & $\begin{array}{c}\text { Collection } \\
\text { dates }\end{array}$ & Origin & $\begin{array}{l}\text { Number } \\
\text { of isolates }\end{array}$ \\
\hline \multicolumn{5}{|l|}{2000} \\
\hline \multirow[t]{5}{*}{ Othello } & \multirow[t]{5}{*}{ OT } & 28 June & Lesions & 15 \\
\hline & & 14 July & Lesions & 3 \\
\hline & & 14 August & Lesions & 14 \\
\hline & & 22 August & Lesions & 16 \\
\hline & & Total & & 48 \\
\hline \multicolumn{5}{|l|}{2001} \\
\hline \multirow[t]{3}{*}{ Warden } & \multirow[t]{3}{*}{ WD } & 26 June & Ascospores & 13 \\
\hline & & 25 July & Lesions & 28 \\
\hline & & Total & & 41 \\
\hline \multirow[t]{5}{*}{ North Pasco } & \multirow[t]{5}{*}{ NP } & 5 June & Ascospores & 8 \\
\hline & & 18 June & Ascospores & 8 \\
\hline & & 22 June & Flowers & 6 \\
\hline & & 13 July & Lesions & 20 \\
\hline & & Total & & 42 \\
\hline \multirow[t]{6}{*}{ Southwest Pasco } & \multirow[t]{6}{*}{ SP } & 30 May & Ascospores & 4 \\
\hline & & 5 June & Ascospores & 7 \\
\hline & & 10 June & Ascospores & 4 \\
\hline & & 22 June & Flowers & 10 \\
\hline & & 29 June & Lesions & 11 \\
\hline & & Total & & 36 \\
\hline Total & & & & 167 \\
\hline
\end{tabular}

performed in a pyramid design, where groups of 10 isolates were paired in all-pairwise combinations; only noncompatible isolates were paired subsequently. Compatible isolates were distinguished by the fusion of mycelia, without an accumulation of red dye in the fusion zone. Three replications were made for each pairing. Incompatible reactions produced a barrage recognized by an obvious red line on the bottom side of petri dishes or by the formation of aerial mycelia along the barrage line. Pairings that yielded questionable reactions were repeated to insure accurate results.

Genetic diversity: Analysis of microsatellite loci. Twenty-five microsatellite primer pairs developed by Sirjusingh and Kohn (28) were used to identify polymorphisms among the $167 \mathrm{~S}$. sclerotiorum isolates. Amplifications were performed following the recommendations of the authors (28). Polymerase chain reaction (PCR) products were separated by electrophoresis on 5\% polyacrylamide denaturing gels and stained with silver nitrate.

PCR amplifications were repeated up to three times on all isolates that failed to produce amplification products. Isolates that failed to produce any amplification products after the third amplification trials were considered to have missing data for the particular loci.

The genetic structure of the population of S. sclerotiorum in the Columbia Basin was analyzed with the analysis of molecular variance (AMOVA), which uses an analysis of variance framework to compute an analog to $\mathrm{F}_{\mathrm{ST}}(\Phi$-statistic) (10). The null hypotheses of a lack of significant differences between fields, collection dates, and origin of isolates (ascospore versus lesion isolates) were tested in Arlequin version 2.000, employing 1,000 permutations to assess the variance of significance components (27).

Potential outcrossing in S. sclerotiorum was assessed by calculating the proportion of significant linkage disequilibria between pairs of loci, and the indices of association $\left(I_{A}\right)(7,22)$ for the population of the Columbia Basin, as well as for every field. In highly clonal populations, a departure from linkage equilibrium is observed in studied populations, and higher observed $I_{A}$ values are obtained in clonal populations compared with that of expected $I_{A}$ values in recombining populations.

Linkage disequilibria were computed in Genepop version 3.3 (25), and adjustments for increases in type I error due to the large number of comparisons were made using Bonferroni's sequential corrections method (26). Indices of association were computed in Multilocus version 1.2.2 (1). Recombination cannot be excluded if the observed $I_{A}$ value falls well within the distribution of the indices from artificially generated recombined data sets, which indicates no correlation of alleles across loci. In this study, 300 recombined data sets were created for the comparisons within each field and across the entire population of the Columbia Basin.

Detection of outcrossing. Twelve apothecia were collected in a mustard field north of Pasco, WA, in October 2002, and inverted over a petri dish of $2 \%$ water agar to collect ascospores. From each individual apothecium, 20 germinated ascospores were transferred to PDA and incubated for 2 days at $25^{\circ} \mathrm{C}$ and paired in all possible combinations on PDA amended with red food color-

TABLE 2. List of fungicides and rates used to identify sensitivity of Sclerotinia sclerotiorum isolates from the Columbia Basin of Washington

\begin{tabular}{lccc}
\hline Fungicide & $\begin{array}{c}\text { Active } \\
\text { ingredient }\end{array}$ & $\begin{array}{c}\text { Label rate } \\
(\text { liter/ha })\end{array}$ & $\begin{array}{c}\text { Rates used } \\
(\mu \mathrm{g} \text { a.i./ml of culture medium })\end{array}$ \\
\hline Botran 5F & Dichloran & 4.75 & $\begin{array}{l}1.45,0.145,1.45 \times 10^{-2}, \\
\end{array}$ \\
& & & $2.9 \times 10^{-3}$ \\
Blocker 5F & Quintozene & 10.67 & $6.3 \times 10^{-2}$ \\
Omega 500F & Fluazinam & 0.591 & $6.32 \times 10^{-2}, 6.32 \times 10^{-3}$, \\
& & & $6.32 \times 10^{-4}, 1.26 \times 10^{-4}$ \\
Rovral 4F & Iprodione & 2.375 & $2.7 \times 10^{-2}, 2.7 \times 10^{-3}$, \\
& & & $2.7 \times 10^{-4}, 5.5 \times 10^{-5}$ \\
\hline
\end{tabular}


ing to test for differences in mycelial compatibility. Ascospores generated by self-fertilization are clones and belong to the same MCG, whereas those generated by outcrossing have different MCGs (19).

Response to temperature and fungicides. Representatives of all 82 recovered MCGs were tested for in vitro growth at a range of temperatures and fungicide concentrations (Table 2). A total of 100 isolates were grown on PDA, and 2-mm-diameter mycelial plugs from actively growing colonies were transferred to PDA plates and subjected to $10,18,25$, and $33^{\circ} \mathrm{C}$ in the dark for 3 days. Plates were arranged in a randomized complete block design (RCB) with three replicates. Mycelial plugs were transferred to PDA plates amended with iprodione, dichloran, quintozene, and fluazinam (Table 2). Concentrations were based on label recommendations and serial dilutions. Three replicates for each isolate-fungicide treatment were prepared, and petri dishes were arranged in an RCB design and incubated in the dark at $25^{\circ} \mathrm{C}$ for 3 days. Following the 3 -day incubation, radial growths of the isolates were compared with the same isolate growing on nonamended PDA. Two colony diameter measurements were made at a $90^{\circ}$ angle with Vernier calipers, and the mean diameter was retained. The experiments were repeated two times.

Colony diameter data were analyzed by one-way analyses of variance (ANOVA) using PROC GLM in SAS (version 8.1, SAS Institute, Cary, NC). Fungicides and temperatures served as treatments while colony diameter functioned as observational units. Because data were not normally distributed, a rank transformation was implemented and the ANOVA was computed on the ranks.

Aggressiveness. Ten isolates representing MCG 1, five isolates representing MCG 6, five isolates representing MCG 10, and 15 isolates randomly selected from the population in the Columbia Basin were used to quantify aggressiveness on potato plants. Isolates used in this study originated from ascospore and lesion samples. Potato plants were propagated from certified seed tubers $(\approx 13$-g seed pieces) in a commercial potting soil mix (Soil Conditioners, Zillah, WA) and subjected to a 16-h photoperiod in the greenhouse at $25 \pm 5^{\circ} \mathrm{C}$. Inoculations were performed on stems approximately $60 \mathrm{~cm}$ in length by attaching potato blossoms colonized with 1 of $36 \mathrm{~S}$. sclerotiorum isolates collected from the Columbia Basin to stems. Blossom colonization was achieved by placing autoclaved blossoms on top of a growing colony of $S$. sclerotiorum on PDA for 3 to 4 days. Each isolate was replicated five times. Colonized blossoms were lightly wrapped with gauze to hold them onto stems and preserve moisture. Plants were subjected to an intermittent mist for $24 \mathrm{~h}$ in mist chambers. Misting was stopped after $24 \mathrm{~h}$ but the plants were kept at above $95 \%$ relative humidity in the mist chambers for an additional $48 \mathrm{~h}$. Ambient temperature was $16 \pm 2^{\circ} \mathrm{C}$ at night and $27 \pm 2^{\circ} \mathrm{C}$ during the day. On the third day postinoculation, plants were removed from the mist chamber and kept at approximately $25^{\circ} \mathrm{C}$ during the day and $18^{\circ} \mathrm{C}$ at night for three additional days. Lesion lengths were measured with Vernier calipers. The experiment was repeated twice.

Length of lesions was analyzed by one-way ANOVA using PROC GLM in SAS. Individual isolates functioned as treatments and lesion length constituted the observational units. Data were not normally distributed and a rank transformation was used in the ANOVA.

\section{RESULTS}

Genetic diversity: Mycelial compatibility. Eighty-two MCGs were identified from 167 potato isolates of S. sclerotiorum. MCG 1, MCG 10, and MCG 6 represented 30.5, 6.6, and 3\% of the isolates, respectively, and were identified in isolates from ascospore, flower, and lesion samples (Fig. 1). Sixty-four MCGs were collected only once, and 16 other groups were collected two to five times. All 167 self-pairings were compatible. Isolates belong- ing to the same MCG had similar (few were identical) to highly variable microsatellite haplotypes.

MCG 1 was collected from all four fields in the 2 years of the study. MCG 10 was present only southwest and north of Pasco, in the southern Columbia Basin. MCG 6 was found only in Warden in the northern Basin.

Genetic diversity: Analysis of microsatellite loci. Eleven of the 25 microsatellite primer pairs used in this study exhibited polymorphisms (Table 3). Data from the 14 monomorphic primers were not included in the statistical analyses. DNA sequence comparisons of polymorphic alleles confirmed that actual differences in repeat motifs were responsible for differences in allele sizes.

Fifteen isolates shared identical haplotypes, three isolates shared one haplotype, and six pairs shared identical haplotypes. In most cases, isolates sharing identical haplotypes did not belong to the same population.

More than $92 \%$ of the variability in the AMOVA was attributable to within subpopulation variability (Table 4). Elevated levels of within-population heterozygosity are very common in highly variable markers, such as microsatellites $(4,14)$. No statistically significant difference was found when dividing isolates by collection year $(P=0.075)$ (Table 4$)$. For this reason, fields and not collection year was considered in further analyses. Differences among the four studied fields were not statistically significant $(P=0.12)$. Differences among ascospore collection dates were significant, but contributed approximately $3.5 \%$ of the variability. When samples were divided as ascospores versus lesion samples within each location, the contribution of the latter two groups to the total variation reached $6.5 \%$ when $P$ was $<0.0001$ (Table 4).

Evidence of clonality was evident in fields OT and NP, where considerable levels of linkage disequilibria were found ( 7 and $14 \%$, respectively) (Table 5) and the observed $I_{A}$ values fell outside the distribution ranges of the artificially recombined data sets (Fig. 2). Conversely, potential outcrossing could not be dismissed in SP and WD, where no evidence for linkage disequilibria among pairs of loci could be detected (Table 5), and observed $I_{A}$ values were included within the distribution intervals of the artificially recombined data sets (Fig. 2). When all samples were

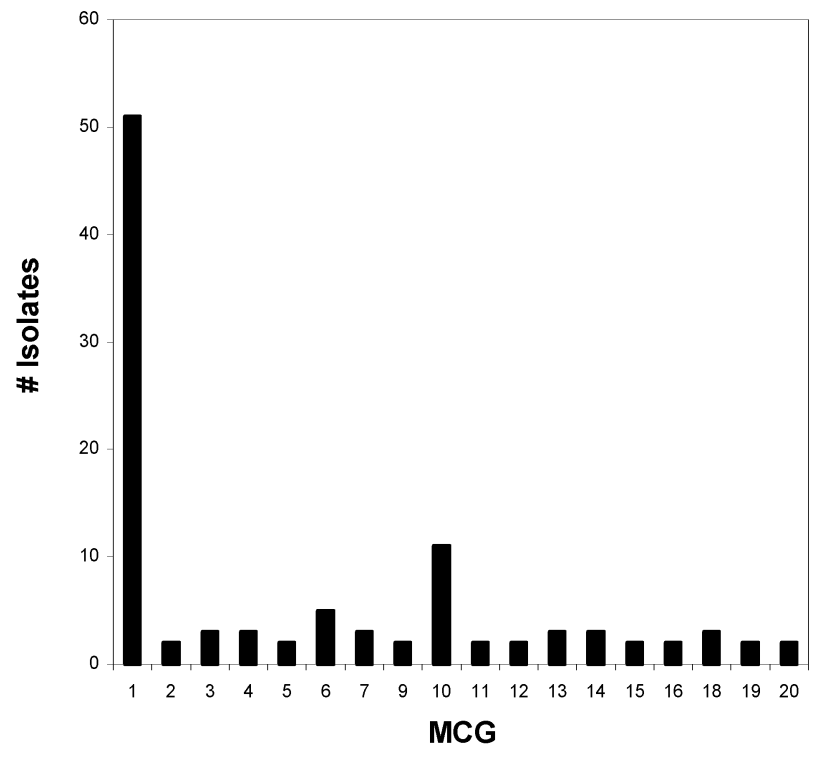

Fig. 1. Histogram of frequencies of the 20 mycelial compatibility groupings (MCGs) including more than one individual out of a population of 167 potato isolates of Sclerotinia sclerotiorum. Nine MCGs included two isolates, six included three isolates, and another 62 MCGs were formed by individual isolates. MCG 1 comprised 51 isolates and was the largest group, MCG 10 contained 11 isolates, and MCG 6 consisted of five isolates. 
combined to look at the population of the Columbia Basin as one unit, clonality was evident (Fig. 2), in line with previous North American reports.

Detection of outcrossing. Three out of twelve apothecia collected from the Columbia Basin in October 2002 harbored ascospores belonging to different MCGs. A minimum of three MCGs (from 20 ascospores/apothecium) were obtained in each one of the three apothecia. Differences of MCG in one apothecium are considered evidence of outcrossing, thus substantiating the outcome of the microsatellite analyses.

Response to temperature and fungicides. Fungal growth did not occur in vitro at labeled rates of iprodione, dichloran, and fluazinam. Mycelial plugs transferred from fungicide-amended PDA plates to nonamended plates failed to grow when transferred from iprodione-amended plates, demonstrating a fungicidal activity. In contrast, plugs transferred from dichloran- and fluazinamamended plates grew normally after transfer to nonamended PDA, thus demonstrating a fungistatic activity. All isolates grew at $0.145 \mu \mathrm{g}$ of dichloran per $\mathrm{ml}$ and at $2.7 \times 10^{-4} \mu \mathrm{g}$ of iprodione per $\mathrm{ml}$, while mycelial growth did not occur at $1.26 \times 10^{-4} \mu \mathrm{g}$ of fluazinam per $\mathrm{ml}$. Differences in colony diameters were not observed among isolates at all fungicide concentrations at which growth was not inhibited. Quintozene failed to prevent the growth of $S$. sclerotiorum colonies at the concentration equivalent to the highest field rate (10.67 liters of Blocker 5F per ha); growth reduction was $20 \%$ compared with that of nonamended controls.

S. sclerotiorum grew normally at 10,18 , and $25^{\circ} \mathrm{C}$, but failed to grow at $33^{\circ} \mathrm{C}$. Colony growth was delayed by 3 days at $10^{\circ} \mathrm{C}$, but picked up rapidly thereafter. Colonies filled the 9 -cm-diameter petri dishes in 3 days at 18 and $25^{\circ} \mathrm{C}$ and in 8 days at $10^{\circ} \mathrm{C}$. Daily measurements of colony diameters did not differ at any temperature used during the entire experiment.

Aggressiveness. Lesions were apparent on stems 3 days postinoculation, and the mean lesion length was $15 \mathrm{~mm}$. All isolates produced lesions on potato stems, but lesion size and number of lesions did not differ significantly among isolates $(P>0.05)$.

\section{DISCUSSION}

Ascospores were abundant at initial full bloom in the sampled fields and were regularly captured on top of plant canopies between May and mid-July. Colonies produced by germinating ascospores mostly belonged to different MCGs (Fig. 3). S. sclerotiorum in the Columbia Basin showed a higher level of haplotype diversity compared with that of previous reports $(8,15,17)$.

Three of the twelve apothecia tested in this study showed evidence of outcrossing. Furthermore, linkage disequilibrium and index of association analyses further confirm a potential for outcrossing occurring in the Columbia Basin, albeit in the two localities where such a hypothesis could not be rejected (Table 5; Fig. 2). The test of ascospores for differences in MCGs and microsatellite analyses do not shed light on the reasons for the occurrence of outcrossing, which remain to be elucidated. It is possible that microconidia, produced by $S$. sclerotiorum, but unable to germinate (18) may act as spermatia, similar to reports in closely related genera (9). Further research is needed to investigate the extent and mechanisms of outcrossing in the Columbia Basin.

It is conceivable, but not ascertained, that environmental or agricultural conditions in the Canadian plains could prevent de-

TABLE 3. List of microsatellite primers showing polymorphism with Sclerotinia sclerotiorum isolates ${ }^{\mathrm{a}}$

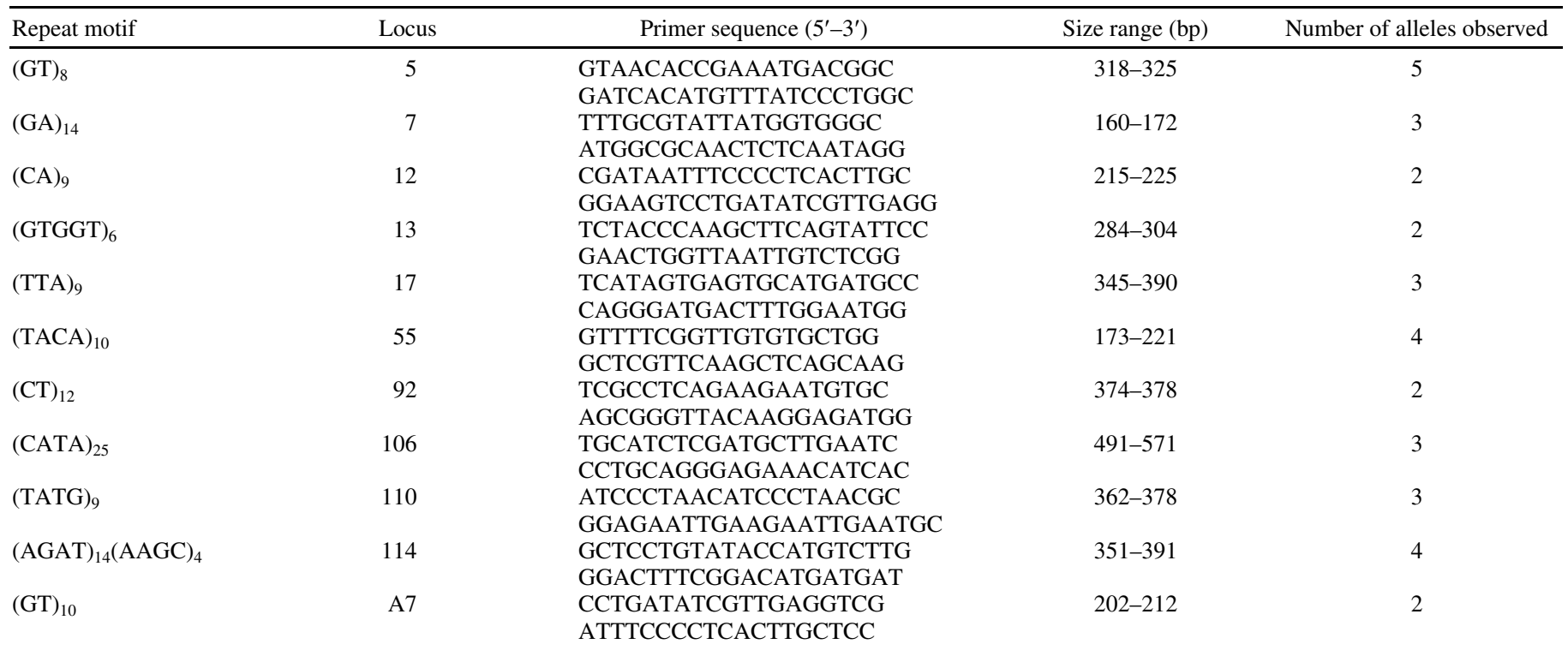

a Eleven of 25 microsatellite loci published by Sirjusingh and Kohn (28) were polymorphic, and data from those loci were used in the analysis of the population in the Columbia Basin of Washington.

TABLE 4. Analysis of molecular variance of Sclerotinia sclerotiorum from four potato fields in the Columbia Basin of Washington and comparison of ascospore- and lesion-derived isolates

\begin{tabular}{lrrccc}
\hline $\begin{array}{l}\text { Source } \\
\text { of variation }\end{array}$ & df & $\begin{array}{c}\text { Sum of } \\
\text { squares }\end{array}$ & $\begin{array}{c}\text { Variance } \\
\text { component }\end{array}$ & $\begin{array}{c}\text { Percent } \\
\text { variation }\end{array}$ & $P$ value $^{\mathrm{a}}$ \\
\hline $\begin{array}{l}\text { Among fields } \\
\text { Ascospores vs. }\end{array}$ & 2 & 12.587 & 0.02536 & 1.12 & 0.12 \\
$\quad$ lesions & 3 & 14.247 & 0.14773 & 6.53 & $<0.001$ \\
Within fields & 113 & 236.242 & 2.09063 & 92.35 & $<0.001$ \\
Total & 118 & 263.076 & 2.26373 & $\ldots$ & $\ldots$ \\
\hline
\end{tabular}

a Nonparametric randomization tests, with 1,000 permutations.
TABLE 5. Percentages of linkage disequilibria significantly different from zero in four populations of $S$. sclerotiorum from the Columbia Basin of Washington

\begin{tabular}{lccc}
\hline Field & $\begin{array}{c}\text { Number of } \\
\text { isolates }\end{array}$ & $\begin{array}{c}\text { Fisher's exact } \\
\text { test }(P<0.05)\end{array}$ & $\begin{array}{c}\text { Bonferroni's se- } \\
\text { quential corrections }\end{array}$ \\
\hline Southwest Pasco & 36 & $5.50 \%$ & 0 \\
North Pasco & 42 & $26.20 \%$ & $7.14 \%$ \\
Othello & 48 & $29.16 \%$ & $14.60 \%$ \\
Warden & 41 & $12.20 \%$ & 0 \\
Total & 167 & $\ldots$ & $\ldots$ \\
\hline a A total of 55 pairwise comparisons of 11 polymorphic loci, computed $P$ \\
\multicolumn{2}{l}{ value of 0.0009. }
\end{tabular}


tectable levels of outcrossing. The high diversity of host crops in the Columbia Basin and the milder winters might offer the fungus more favorable conditions for outcrossing. Reports from peach in California indicate the recovery of 2 out of 42 apothecia with evidence of outcrossing (16), revealing a potential for the occurrence of outcrossing in warmer regions.

The population of S. sclerotiorum in the Columbia Basin seems highly clonal when analyzed as one unit with the linkage disequilibrium and index of association methods. It would be of great benefit to compare a number of close locations at various dates in other regions of North America to test for potential outcrossing in areas where this phenomenon was not detected. It is conceivable that outcrossing is overshadowed by the epidemic nature of the pathogen. Even with some level of outcrossing occurring frequently in a population, the wide dispersal of a few successful genotypes leads to linkage disequilibria (22). Subtle differences

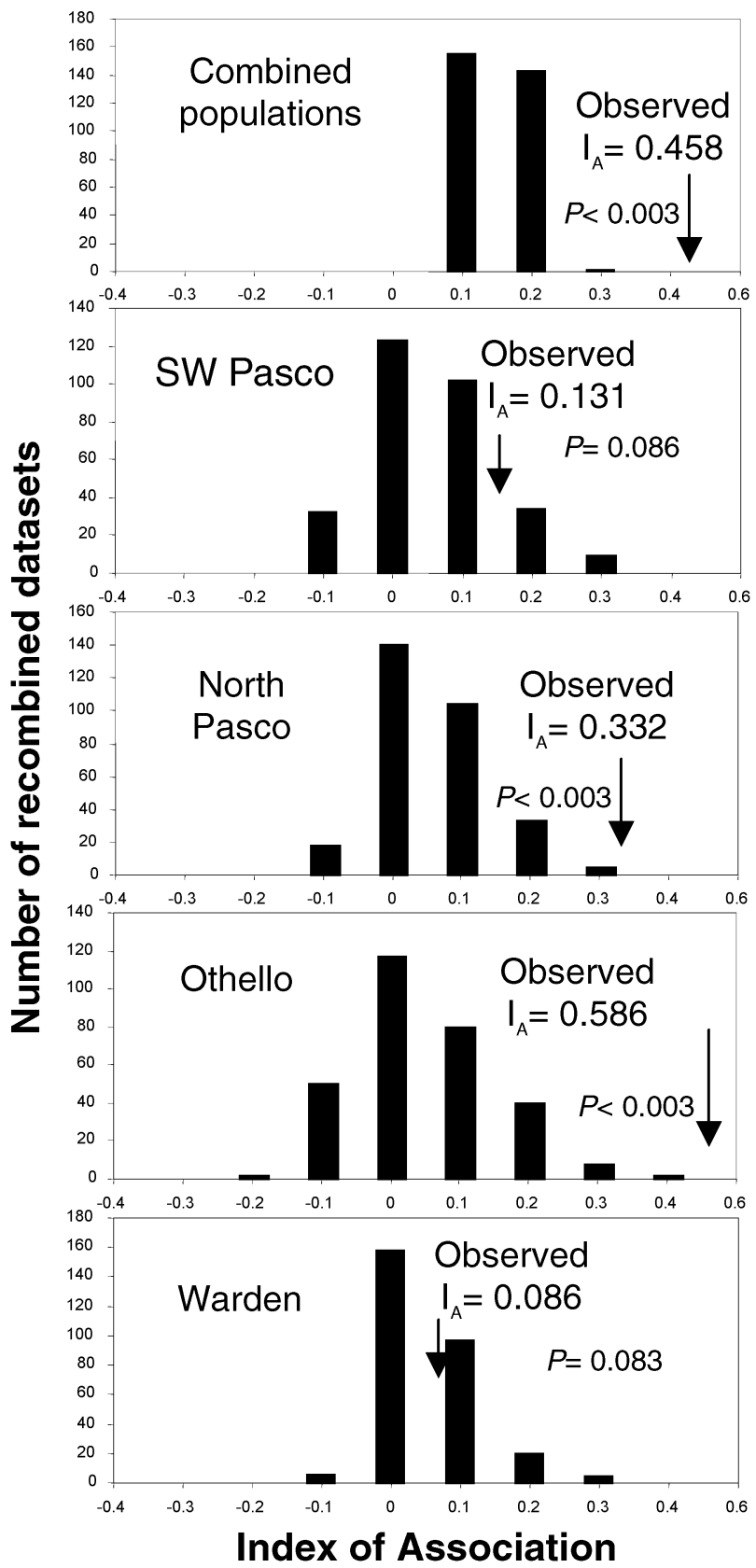

Fig. 2. Observed indices of association compared with indices of association from 300 artificially recombined data sets for the combined populations of Sclerotinia sclerotiorum in the Columbia Basin of Washington and for the four individual populations. Arrows indicate the emplacement of the observed indices in the distribution of 300 artificially generated indices. in infectiveness and fitness that were not picked up in this, and previous, reports could explain the ability of certain genotypes of S. sclerotiorum to successfully establish themselves over large areas. Such aspects were not addressed by this study and remain to be clarified.

AMOVA showed evidence of a statistically significant population structuring, with minimal impact on the total variability of the population. The variability was highest (more than 92\%) within each of the collection dates, as evidenced by Figure 3, where each of the 11 ascospores captured on the petri dish belongs to a different MCG. A combination of outcrossing and migration may account for part of the observed high variability. Gene flow could be achieved by dispersal of sclerotia in vegetative material or by ascospore transport in air currents. Seeds of a variety of crops (vegetables, legumes, grain crops, etc.) are imported for growing in the Columbia Basin; seed batches could contain sclerotia of S. sclerotiorum. Migration of isolates into, and within, the Columbia Basin was not investigated in this study.

Isolates from potato collected in the Columbia Basin did not differ in aggressiveness on potato plants or in vitro response to fungicides and temperature gradients. Differences in isolate aggressiveness were reported from canola populations in Canada, but selection based on such a phenomenon was ruled out (15). The lack of differentiation in the current study could be induced by the nature of the test itself. A test based on the production of oxalic acid, reported to be the pathogenicity determinant in S. sclerotiorum (12), may potentially provide further insight.

In addition to the failure to detect differences in aggressiveness among isolates tested on potato plants, we failed to find differences in growth at various temperatures or sensitivity to four fungicides at a wide range of concentrations. The lack of differentiation among isolates at the phenotypic level is concurrent with findings by Kohn (19), who observed phenotypic uniformity of S. sclerotiorum isolates collected in agricultural locations in Canada and Norway. Such observations are essential for the control of $S$. sclerotiorum on potato and other crops in the Columbia Basin. Fears of potato growers of having to deal with an increased aggressiveness, or a reduced sensitivity to fungicides, seem unsubstantiated by our findings.

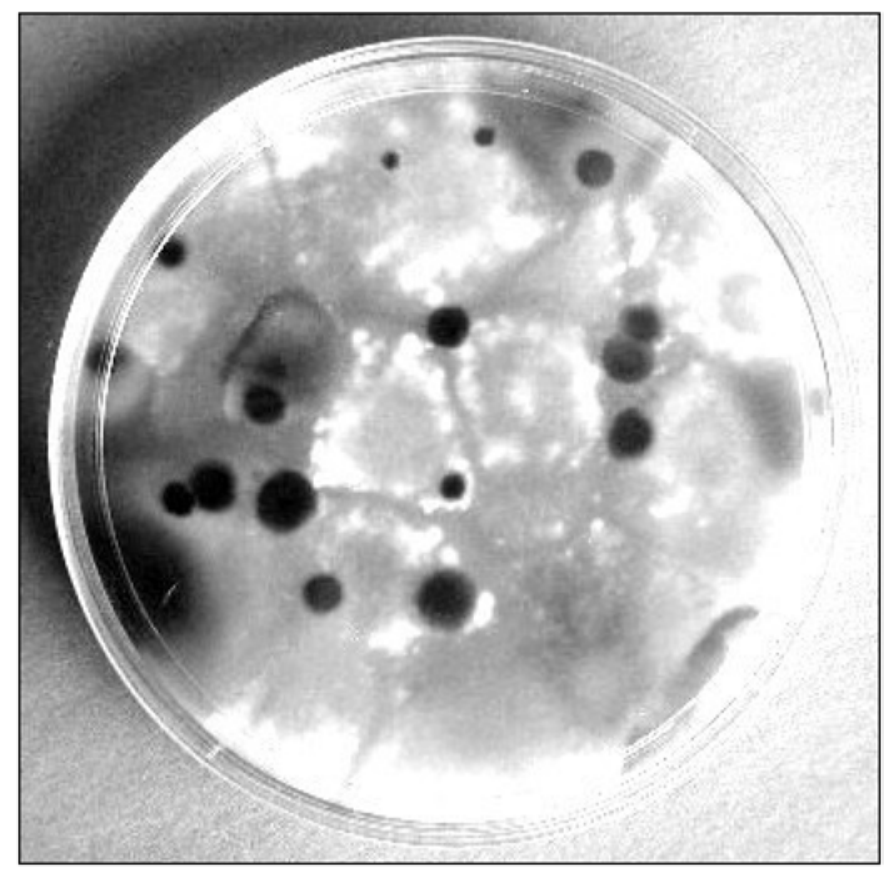

Fig. 3. Colonies from Sclerotinia sclerotiorum ascospores captured on top of a plant canopy. Colonies belong to different mycelial compatibility groupings, evident by the formation of barrages between mycelia. 
Substantial gaps remain in understanding the extent of differences among S. sclerotiorum populations in various regions of North America, and of the mechanisms controlling homothallism and outcrossing in S. sclerotiorum. Moreover, more research is needed to investigate the potential impacts of outcrossing on epidemics and disease management.

\section{ACKNOWLEDGMENTS}

We thank the Washington State Potato Commission for financial support; F. Dugan, G. Grove, and W. Chen for critical review of the manuscript; J. F. Crow for gracious suggestions and recommendations; and the editors and anonymous reviewers of Phytopathology for the constructive suggestions that allowed this manuscript to make it to publication. Plant Pathology New Series 0362, Department of Plant Pathology, College of Agriculture and Home Economics Research Center, Project 0678, Washington State University, Pullman.

\section{LITERATURE CITED}

1. Agapov, P. M., and Burt, A. 2001. Indices of multilocus linkage disequilibrium. Mol. Ecol. Notes. 1:101-102.

2. Anderson, J. B., and Kohn, L. M. 1995. Clonality in soilborne, plant pathogenic fungi. Annu. Rev. Phytopathol. 33:369-391.

3. Atallah, Z. K., and Johnson, D. A. 2004. Development of Sclerotinia stem rot in potato fields in South-Central Washington. Plant Dis. 88:419423.

4. Balloux, F., Brünner, H., Lugon-Moulin, N., Hausser, J., and Goudet, J. 2000. Microsatellites can be misleading: An empirical and simulation study. Evolution 54:1414-1422.

5. Balloux, F., and Lugon-Moulin, N. 2002. The estimation of population differentiation with microsatellite markers. Mol. Ecol. 11:155-165.

6. Boland, G. J., and Hall, R. 1994. Index of plant hosts of Sclerotinia sclerotiorum. Can. J. Plant Pathol. 16:93-108.

7. Burt, A., Carter, D. A., Koenig, G. L., White, T. J., and Taylor, J. W. 1996. Molecular markers reveal cryptic sex in the human pathogen Coccidioides immitis. Proc. Natl. Acad. Sci. 93:770-773.

8. Cubeta, M. A., Cody, B. R., Kohli, Y., and Kohn, L. M. 1997. Clonality in Sclerotinia sclerotiorum on infected cabbage in eastern North Carolina. Phytopathology 87:1000-1004.

9. Drayton, F. L. 1932. The sexual function of the microconidia in certain Discomycetes. Mycologia 24:345-348.

10. Excoffier, L., Smouse, P. E., and Quattro, J. M. 1992. Analysis of molecular variance inferred from metric distances among DNA haplotypes: Application to human mitochondrial DNA restriction data. Genetics 131:479-491.

11. Gaggiotti, O. E., Lange, O., Rassmann, K., and Gliddon, C. 1999. A comparison of two indirect methods for estimating average levels of gene flow using microsatellite data. Mol. Ecol. 8:1513-1520.

12. Godoy, G., Steadman, J. R., Dickman, M. B., and Dam, R. 1990. Use of mutants to demonstrate the role of oxalic acid in pathogenicity of
Sclerotinia sclerotiorum on Phaseolus vulgaris. Physiol. Mol. Plant Pathol. 37:179-191.

13. Guttierez, W. A., and Shew, H. D. 1998. Identification and quantification of ascospores as the primary inoculum for collar rot of greenhouseproduced tobacco seedlings. Plant Dis. 82:485-490.

14. Hedrick, P. W. 1999. Perspective: Highly variable loci and their interpretation in evolution and conservation. Evolution 53:313-318.

15. Kohli, Y., Brunner, L. J., Yoel, H., Milgroom, M. G., Anderson, J. B., Morrall, R. A. A., and Kohn, L. M. 1995. Clonal dispersal and spatial mixing in populations of the plant pathogenic fungus, Sclerotinia sclerotiorum. Mol. Ecol. 4:69-77.

16. Kohli, Y., and Kohn, L. M. 1998. Random association among alleles in clonal populations of Sclerotinia sclerotiorum. Fungal Genet. Biol. 23:139-149.

17. Kohli, Y., Morrall, R. A. A., Anderson, J. B., and Kohn, L. M. 1992. Local and trans-Canadian clonal distribution of Sclerotinia sclerotiorum on canola. Phytopathology 82:875-880.

18. Kohn, L. M. 1979. A monographic revision of the genus Sclerotinia. Mycotaxon 9:365-444.

19. Kohn, L. M. 1995. The clonal dynamic in wild and agricultural plantpathogen populations. Can. J. Bot. 73:S1231-S1240.

20. Kohn, L. M., Carbone, I., and Anderson, J. B. 1990. Mycelial interactions in Sclerotinia sclerotiorum. Exp. Mycol. 14:255-267.

21. Kohn, L. M., Stasovski, E., Carbone, I., Royer, J., and Anderson, J. B. 1991. Mycelial incompatibility and molecular markers identify genetic variability in field populations of Sclerotinia sclerotiorum. Phytopathology 81:480-485.

22. Maynard-Smith, J., Smith, N. H., O'Rourke, M., and Spratt, B. F. 1993. How clonal are bacteria? Proc. Natl. Acad. Sci. 90:4384-4388.

23. Powell, J. F., and Vargas, J. M. 2001. Vegetative compatibility and seasonal variation among isolates of Sclerotinia homoeocarpa. Plant Dis. 85:377-381.

24. Purdy, L. H. 1979. Sclerotinia sclerotiorum: History, diseases and symptomatology, host range, geographic distribution, and impact. Phytopathology 69:875-880.

25. Raymond, M., and Rousset, F. 1995. Genepop (Version 1.2), a population genetics software for exact tests and ecumenism. J. Hered. 86:248-249.

26. Rice, W. R. 1989. Analyzing tables of statistical tests. Evolution 43:223225.

27. Schneider, S., Roessli, D., and Excoffier, L. 2000. Arlequin version 2.000: A software for population genetics data analysis. Genetics and Biometry Laboratory, University of Geneva, Switzerland.

28. Sirjusingh, C., and Kohn, L. M. 2001. Characterization of microsatellites in the fungal plant pathogen, Sclerotinia sclerotiorum. Mol. Ecol. Notes. 1:267-269.

29. Steadman, J. R., Marcinkowska, J., and Rutledge, S. 1994. A semi-selective medium for isolation of Sclerotinia sclerotiorum. Can. J. Plant Pathol. 16:68-70.

30. Valdes, A. M., Slatkin, M., and Freimer, N. B. 1993. Allele frequencies at microsatellite loci: The stepwise mutation model revisited. Genetics 133:737-749.

31. Vandenkoornhuyse, P., Leyval, C., and Bonnin, I. 2001. High genetic diversity in arbuscular mycorrhizal fungi: Evidence for recombination events. Heredity 87:243-253. 